\title{
Emerging Barriers in E-Government Implementation
}

\author{
Spyros Angelopoulos ${ }^{1}$, Fotis Kitsios ${ }^{2}$, Petros Kofakis ${ }^{3}$, and Thanos Papadopoulos ${ }^{4}$ \\ ${ }^{1}$ Information Systems and Management Group, Warwick Business School, \\ The University of Warwick, Coventry, CV4 7AL, UK \\ spyros.angelopoulos.09@mail.wbs.ac.uk \\ ${ }^{2}$ Department of Technology Management, University of Macedonia, \\ Loggou-Tourpali, 59200 Naousa, Greece \\ kitsios@uom.gr \\ ${ }^{3}$ KP Research \& Consultancy, P.O. Box 3138, 10210 Athens, Greece \\ kofakis@gmail.com \\ ${ }^{4}$ Knowledge and Information Systems Management Group, Centre for Operational Research, \\ Management Science and Information Systems (CORMSIS), School of Management, \\ University of Southampton, SO17 1BJ Southampton, UK \\ a.papadopoulosesoton.ac.uk
}

\begin{abstract}
This study presents the outcomes of a qualitative case study of implementing e-government Information Systems within the national digital strategy in a governmental organisation, following action research. The results show that although e-government is a socio-technical process and has to accommodate the views of all stakeholders, this is questioned in practice. No matter if e-government needs to be a tool for decentralisation and democratisation, this scope may be rendered futile due to the fundamental role of the political support required to secure future funds for implementation. While focusing on the changes in business processes that have to be considered by governmental institutions to successfully implement e-government, the need for a holistic model, which can embrace the back- and front- office, and be linked to the real citizens' needs, arises.
\end{abstract}

Keywords: e-government, public sector organisation, digital strategy.

\section{Introduction}

E-government is a phenomenon of an era that e-business is becoming vital in both the private sector and in the governmental institutions. It utilises Information and Communication Technologies (ICT) in order to accomplish reform by fostering transparency, eliminating distance as well as other divides, and empowering people to participate in the political processes that affect their lives. Hence, it is regarded as a fundamental enabler of greater citizen involvement in civic and democratic matters in the sense of direct democracy as the one practiced in the city-states of ancient Greece [2].

The use of ICT as a tool for change in the structures and processes of governmental organizations and the subsequent attempt to enable the exchange of information 
amongst citizens, businesses and government may result in improved efficiency, convenience as well as better accessibility of public services. Ubiquity postulates the omnipresence of networking; an unbounded and universal network [3]. Therefore, ample and ubiquitous access to ICT is essential for uniform and consistent diffusion of innovation. This, however, can only be implemented through the sharing of ICT resources across governments and their citizens. Hence, the implementation of egovernment as a means for facilitating information and knowledge exchange amongst all the aforementioned stakeholders remains a challenge.

The structure of the paper is as follows: after a discussion of the barriers of the egovernment concept, the paper explicates the methodological and conceptual rectifications utilised to address the issue of under-specification in the e-government literature. A case study was followed in a Governmental Organization (GO) ${ }^{1}$ to enhance the understanding of e-government policy processes and actors and correlate e-government to mainstream public administration research. The implementation of Information Technology (IT) projects in the public sector involves multiple stakeholders, such as administrators, policy-makers and the end-users. Defining the intentions and responsibilities of different stakeholders within a national digital strategy can become a really difficult task and differences in their agendas may eventually render the project futile. The uniqueness of the case study lies in studying and discussing issues related to e-government implementation at the highest decision level. The last section discusses these issues and concludes the paper.

\section{Barriers in E-Government Implementation}

Research in the past has investigated issues in respect to the implementation of egovernment using diffusion models. For instance, by using Diffusion Theory [25], studies have focused on the adoption of IT in the public sector [5], [14], [22], [23] suggesting inter alia, that the size of administration and professionalism are the primary determinants of the adoption of computer technology. Rogers [25] presents five categories of determining variables for the rate of adoption: perceived attributes of the innovation, type of innovation decision, communication channels, nature of the social system and extent of the change agent's promotion efforts. Choudrie and Lee [9] found that the use of broadband connection within government departments and agencies improved the QoS and encouraged previously bureaucratic organisations to re-engineer the way services are delivered to citizens. However, no single diffusion model best explains all cases [22].

The Information Systems (IS) Success Model [11] and the Technology Acceptance Model (TAM) [10] suggests another means to study the implementation of egovernment by measuring perceived usefulness and perceived ease of use influence one's attitude towards system usage. The success factors presented in TAM have to do mainly with the acceptance of organisational software, but have been tested for various users and types of systems [30] [31], and user adoption of e-commerce [15], [21]. However, TAM constructs represent the subjective user assessments of a system and may not be representative of its objective acceptance [6].

\footnotetext{
${ }^{1}$ The name of the Organization is not revealed for confidentiality reasons.
} 
Barriers, however, to the success of IS and e-government concern, for instance, the high cost or the low security of the needed infrastructure and can impede its implementation and adoption. The integration of various IT applications and components inside and outside the organisational boundary remains costly and timeconsuming due to the heterogeneity of the computing environments involved in public-sector organisations [26]. Literature (e.g. [4], [12]) agrees that governments face a shortage of technical infrastructure. This shortage presents a significant barrier in the development of the capabilities of government organisations to provide online services and transactions.

A frequently cited barrier in the literature seems to be the need for security and privacy in an e-government strategy [15]. The shortage of IT skills is also a barrier, which contends many challenges regarding the efficiency of a public administration to provide innovative e-government services [8], [18]. Finally, a major barrier to the adoption and implementation of e-government is funding [18], which also relates to the business procedure of government, management strategy and organisational culture [19].

Organisational barriers relate to structural issues such as fragmentation, poor relations and communication between the functional departments, and an acceptance of the strategic benefits of new initiatives by the senior management (e.g. [1]). Nevertheless, despite the existing literature on the implementation of e-government, there is a need for more research to be conducted. Scholars of the discourse have not shed enough light on the development of new services in e-government [2]. Various initiatives investigate the application of quality management principles to the delivery of public e-services [17], but manifold problems related to their quality still exist [13].

The relevant literature is limited on studying the outcomes of projects and hence the political processes underlying e-government development [32]. The major issue is the definition of procedures and data that need to be exchanged at different phases of the process. If these procedures are well defined, then ICT could be applied successfully; and vice-versa, the application of ICT reinforces the use of good practices and standardisation of the e-government implementation process. Therefore, amongst the major questions is to grasp the meaning of e-government and uncover the problems that can emerge during the implementation of a project. To answer this, the authors set out to investigate a case study in GO. Before embarking on the discussion of the case, in the next section the research methodology is explicated.

\section{Research Methodology}

To deal with the research question as outlined in the previous section, this study followed a qualitative case study strategy. Semi-structured interviews were scheduled with the system users, the managers and the governmental leadership of the GO. Thirty interviews were conducted, recorded and transcribed verbatim. The duration of the interviews was about forty-five minutes on average. The themes covered the implementation strategy of e-government and also questions regarding the meaning of e-government for each of the interviewees, the agency and citizens. Action research was chosen as the method for the study [7]. 
Data analysis involved three activities, namely data reduction, data display, and conclusion drawing and verification [20]. Initial codes were assigned to the transcripts based on description; interpretive codes were assigned, later transformed refined into pattern codes $(\mathrm{ibid})$. Themes and patterns emerged and were further refined in the process.

\section{Implementing E-Government Project}

The decision for the implementation of e-government within the GO was taken when the need for a more efficient and effective way of implementing directives and policies occurred. The constant increase in paper documents describing activities and actions to be taken and the time wasted in locating these documents; in addition to further external information needed from other governmental organisations along with internal information from various departments, led to this decision. Before that, the life cycle of a certain issue could begin from a particular document that would be forwarded to specific persons or services for 'execution'. Any immediate action would result in a new document. The completion of all these actions would lead to the objective, which described a final document.

However, one of the most intriguing aspects of the project was the fact that it entailed various stakeholders from various departments. End-users, managers and the board of directors were to be involved. They all had different agendas as well as different timetables, and thus the system had to accommodate their different views. Hence, the complete definition and formal analysis of the existing situation, the priorities, the workflow, the tracing and control of all the activities and procedures were challenges in the study.

The implementation team, consisted of inter-organisational consultants and academic researchers, set out to record the end-user requirements. They had to deliver a definition of the system documents and describe the workflow states specific to the board of directors. The system would ensure the tracking and control of all respective issues and activities. Selected users should be trained in the use of the system, and IT experts would support them.

The analysis showed that six types of activities need to be considered, and in particular those regarding procedures and activities analysis and related to the creation of subject matter, data structures and information; activities regarding the collection and preparation (data entry) or data in the system; those that had to do with the infrastructure of the project, as well as those with application development and the integration of IS. Finally, the last part of the implementation process included the training of all the end-users.

\section{An Overview of the IS from a Technical Perspective}

The development of the IS was a demanding application in the fields of information collection and processing. Due to time and budget constraints it was decided to use open standards, which would allow the interoperability of the application and dependent services. There are several benefits embedded in the use of open-source 
systems and the most important is that they are developed with the use of nonproprietary tools. Working in such environments would eliminate the danger of 'lockin' with specific vendors or software packages. The code of open-source systems could be obtained for free and any commercial support associated with the product would be typically comparable or cheaper than other solutions available in the market. Furthermore, active communities of developers support the open-source solutions. The combination of open platforms and simplicity of customization made integrating open-source content management systems (CMS) with other software considerably easier. Last but not least, most open-source solutions also make use of newer technology [24] with all positive or negative consequences that this may imply.

In the specific project, the requirements and the restrictions set for such an application included an open architecture independent from proprietary systems, which would include capabilities of constant development, update, and extension. The need for the cost to be kept at low levels, since external governmental funding had not been secured and it was only through non-finite internal funding channels that the project could be based on. The system had to be user-friendly and to have a unified, platform-independent user interface. Ubiquitous, easy and direct access to the system without any geographical limitations was the final objective.

The solution made use of distributed systems and intranet. In other words, a Web Server was installed as a central access point for all functions. The basic components of the system therefore were the Web Server, Document Management and Retrieval System, Database server, Project Management System, and a Workflow Management System. Additionally, from the discussion with the end-users, their requirements included a graphical representation of the achievement of the objectives, the progress of all issues and activities as well as resource information; features that would enable them to set activities, actions, duties and timetables for members of the organisation as well as to review activities or actions, request and receive reports from involved parties, analyse and check different scenarios for timetable comparison, and allocate human and financial resources. Finally, the system should set new activities or issues and distribute them to the involved parties or authorities. As part of the system implementation, this study continues with the description of two examples of the use of the system, which reflect real-world case studies of the organisation.

\subsection{Workflow Example 1: Research Institute Foundation}

Among the several responsibilities that rely on the duties of GO is the process of National Research Institute Foundation. Therefore, the first example needs to deal with the required workflow for such a task to be properly completed within the new system. Twenty-one steps, all of them inextricably tied on the process, part the process of foundation. All steps are listed bellow followed by a visual representation of the workflow. The authors feel that the chosen simple and visual way of presenting the framework serves best the study as a whole (Figure 1).

\subsection{Workflow Example 2: Legislation Process}

Processing of new laws is one of the major duties of GO. Legislation processes are marked by original and ongoing negotiations, which tend to be critical to the definition of the political community as well as the development and operation of the 


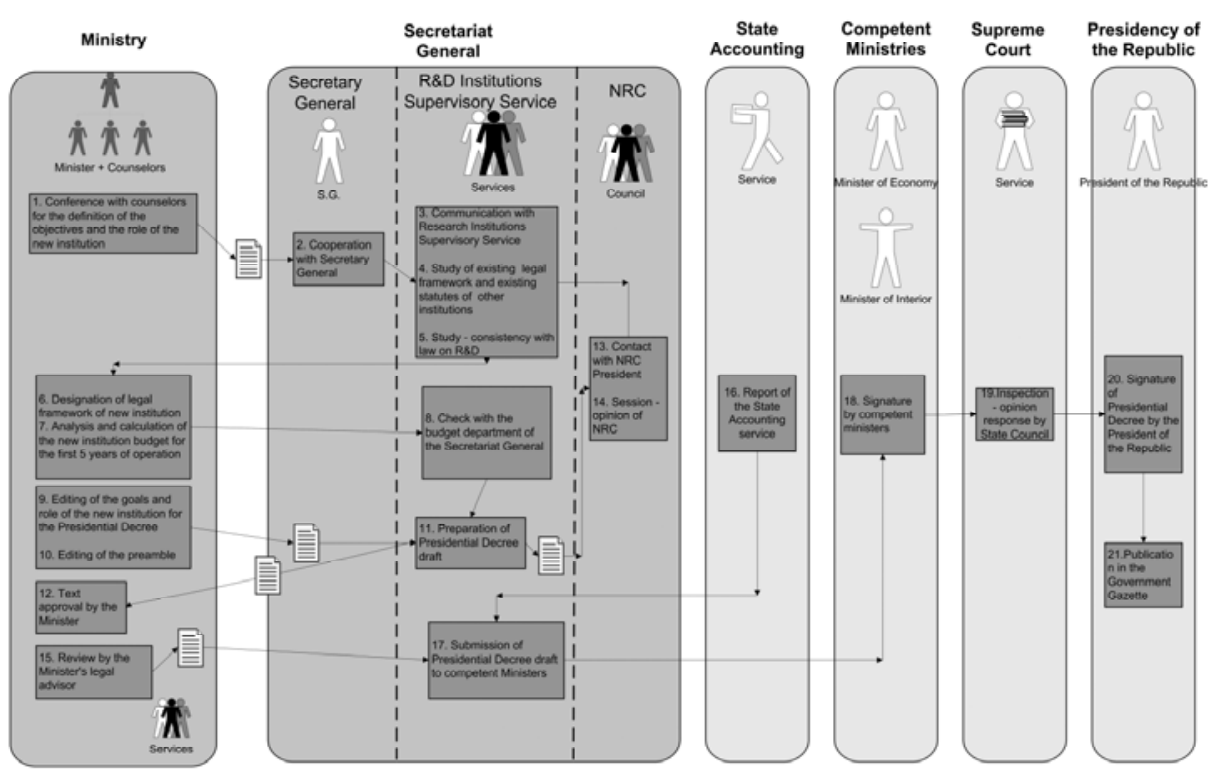

Fig. 1. Workflow of Research Institute foundation case study

constitution, requiring habits of dialogue and compromise [19]. There is often no closure to the constitution-making process [29] and in this context the participation of citizens plays a centric role. Countries with decentralized power tend to be less corrupted [28] and that is the main reason why several developed countries around the world have marked the end of an era and the beginning of new one, under the hegemony of new social forces [19]. Democracy implies the existence of a political community, and as such constitutions followed social forces that promoted democracy; they did not create them from scratch. Therefore, the second example needs to deal with the required workflow for a new law to be properly implemented. Fifteen steps, all of them inextricably tied on the legislation process, part the procedure. All steps are listed bellow followed by a visual representation of the workflow. The visual presentation of the framework enhances this study as a whole (Figure 2).

The implementation took place considering the aforementioned steps after consultation with the users of the system. The steps were to be followed after the system was finally implemented. The aim of the system was to save time and money in three ways: firstly, decisions would be taken on the spot and sent electronically to the corresponding stakeholders; any modifications would be sent immediately for 'execution'; and thirdly, since every decision would be kept electronically, savings would occur in terms of paper use, as well as the GO would eventually go 'greener'.

However, despite the aim of the board of directors and the implementation team to have everything in place, two unexpected events took place, which postponed the implementation. The first had to do with the different agendas of stakeholders that came to the foreground, soon after the system was designed. Senior managers perceived IS/IT in the public sector not as a tool for democratisation and decentralisation but rather as a utility, and their influence was reflected on the budget 


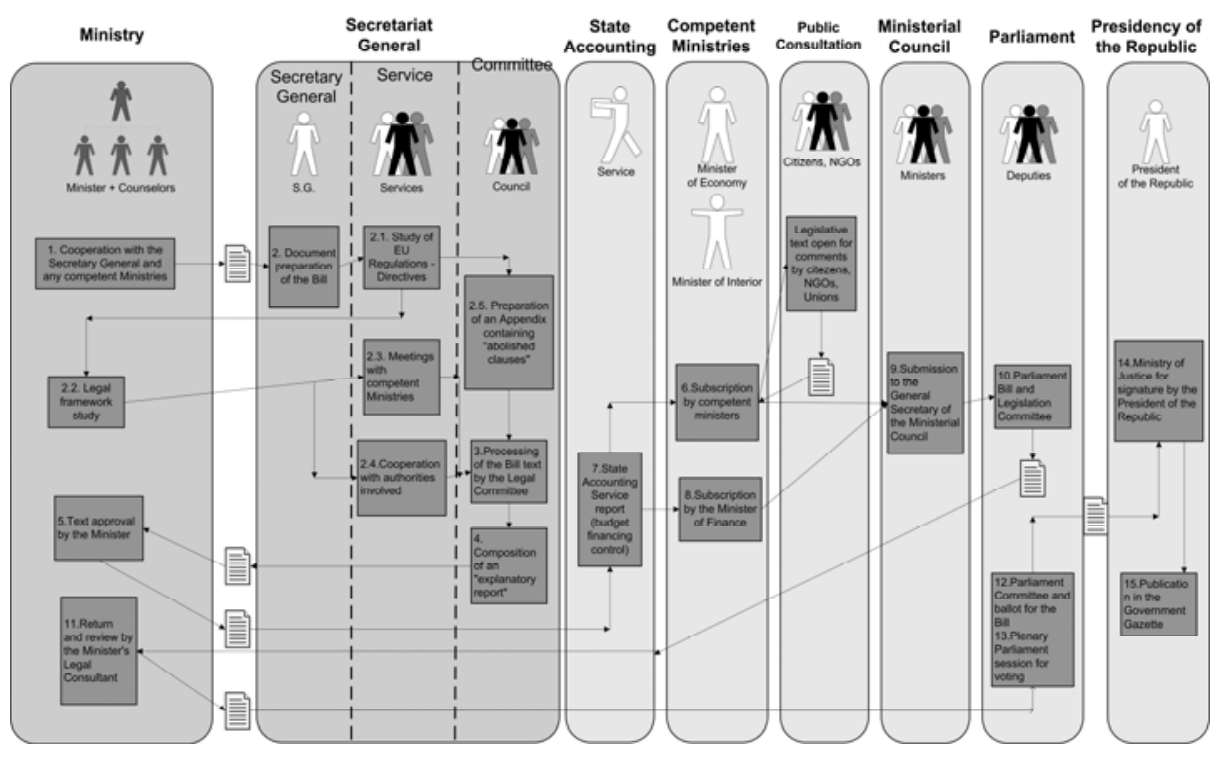

Fig. 2. Workflow of legislation process case study

of the project, where the cost for implementation was dramatically reduced. Moreover, the end-users treated the IS as a potential enemy which could effectively change their way for completing their tasks. Their different agenda compared to the agenda of the board and the governmental leader of GO and the futile attempts to reach consensus brought the project to a permanent standstill. Furthermore, the involved stakeholders had different workloads; this acted as a hindrance mechanism to the implementation. It was really difficult to take them away from their everyday duties and train them to adapt to the new system. The second event was also an outcome of the period in which the implementation took place. Shortly after the user requirements and the implementation process started, the tenure of the governmental lead came to an end and any attempt to reform the GO was cancelled.

\section{Discussion and Conclusion}

E-government is considered to be one of the key contributors to the development of an information society and governments around the world have seen its rapid evolution when there is an integrated approach to planning and implementation of public sector reform. However, the application of ICT in e-government should not be considered as an end in itself. The case study has shown that even if there is political will to implement e-government, the different stakeholder agendas may render it futile. This study has not focused on the role of the heterogeneity of the computer environments involved in public-sector organisations [27], and suggested that egovernment is not simply the use of IT for delivering services to the citizens; instead, the turbulent political environment in which e-government needs to operate plays an important role. 
The success of e-government is dependent on the deeper recognition of complex political and institutional environments in which it is going to operate [32]. Indeed, this was evident in the case from the fact that when the tenure of the governmental lead came to an end, the project was cancelled. It was not, thus, dependent on IT skills [18] or specific software since open source products were chosen. It was, however, dependent on funding (ibid) -related to organisational culture [19]- which stopped after the political support was removed. Hence, to secure the success of future egovernment projects, funding may not be directly related to political support. Projects that are important for improving the efficiency of decision-making and improvements in everyday working practices would be implemented, irrespectively of any changes in the political / governmental leadership.

Additionally, this study makes a case for the changing agendas of the participating stakeholders. In particular, the initial support of the stakeholders, replaced in the later stages of the project due to changes in their working practices indicates that the managerial concern needs to be focused not only on the acceptance of the strategic benefits of new initiatives by the senior management [1], but also by end users, since the investment aims at modernising the organization at all levels [16].

As an addition to the current status of e-government, future work needs to answer the dilemma whether e-government is really a tool for decentralization and democratization or the result of a socio-technical process towards a new model of public administration; an answer will boost the evolution of e-government and provide citizens with effective access to better quality services. Finally, one of the basic concerns is business process management in governmental institutions to successfully implement e-government principles. Therefore, future research needs to focus on a holistic model, which can embrace the back- and front-office, and be linked to the real citizens' needs.

\section{References}

1. Aichholzer, G., Schmutzer, R.: Organisational challenges to the development of electronic government. In: 11th International Workshop on Database and Expert Systems Applications. IEEE Computer Society, Los Alamitos (2000)

2. Angelopoulos, S., Kitsios, F., Papadopoulos, T.: Identifying Critical Success Factors in eGovernment: A New service development approach. Transforming Government: People, Process and Policy 4(1), 95-118 (2010)

3. Angelopoulos, S., Kitsios, F., Babulak, E.: From e to u: Towards an innovative digital era. In: Kotsopoulos, S., Ioannou, K. (eds.) Heterogeneous Next Generation Networking: Innovations and Platform, pp. 427-444 (2008)

4. Bourn, J.: Better Public Services Through E-Government. The National Audit Office, London (2002)

5. Brudney, J., Selden, S.: The adoption of innovation by smaller local governments: the case of computer technology. American Review of Public Administration 25, 71-86 (1995)

6. Carter, L., Belanger, F.: The utilization of e-government services: citizen trust, innovation and acceptance factors. Information Systems Journal 15, 5-25 (2005)

7. Checkland, P.: Systems Thinking, Systems Practice. Wiley, Chichester (1981) 
8. Chen, Y., Gant, J.: Transforming local e-government services: the use of application service providers. Government Information Quarterly 18(4), 343-355 (2001)

9. Choudrie, J., Lee, H.: Broadband development in South Korea: institutional and cultural factor. European Journal of Information Systems 13(2), 103-114 (2004)

10. Davis, F.: Perceived usefulness, perceived ease of use and user acceptance of information technology. MIS Quarterly 13, 319-340 (1989)

11. DeLone, W.H., McLean, E.R.: Information systems success: The quest for the dependent variable. Information Systems Research 3(1), 60-95 (1992)

12. Dillon, J., Pelgrin, W.: E-Government/Commerce in New York State, Office of Technology, New York, NY (2002)

13. EU DG Information Society.: Top of the Web: user satisfaction and usage survey of egovernment services, DG Information Society, European Commission (2004),

http: / / www. eprocnet.gov. ie/other-documents /

topof thewebsurveyresults.pdf/

14. Elliman, T., Irani, Z., Love, P.E.D., Jones, S., Themistocleous, M.: Evaluating egovernment: Learning from the Experiences of Two UK Local Authorities. Information Systems Journal, special issue on e-Government 15, 61-82 (2005)

15. Gefen, D., Pavlou, P.A., Warkentin, M., Rose, G.M.: EGovernment Adoption. In: The Proceedings of the Eighth Americas Conference on Information Systems (2002)

16. Hackney, R., Jones, S., Irani, Z.: eGovernment Information Systems Evaluation: Conceptualising 'Customer Engagement'. In: eGovernment Workshop, eGOV'05 (2005)

17. Halaris, C., Magoutas, B., Papadomichelaki, X., Mentzas, G.: Classification and Synthesis of Quality Approaches in e-Government Services. Internet Research 17(4), 378-401 (2007)

18. Heeks, R.: Understanding e-Governance for development, The University of Manchester, Institute for Development Policy and Management: iGovernment Working Papers Series, Number 11/2001 (2001),

http: / /unpan1.un.org/intradoc/groups/public/

documents/NISPAcee/UNPAN015484.pdf

19. Lenk, K., Traunmuller, R.: A framework for electronic government. Paper Presented at 11th International Workshop on Database and Expert Systems Applications. IEEE Computer Society, London (2000)

20. Miles, M.B., Huberman, A.M.: Qualitative Data Analysis: An Expanded Sourcebook. Sage, Thousand Oaks (1994)

21. Moon, J., Kim, Y.: Extending the TAM for a worldwide-web context. Information and Management 28, 217-230 (2001)

22. Moon, J., Norris, D.: Does managerial orientation matter? The adoption of reinventing government and e-government at the municipal level. Information Systems Journal 15, 43 60 (2005)

23. Norris, D.F., Campillo, D.: Factors Affecting Innovation Adoption by City Governments: The Case of Leading Edge Information Technologies, Maryland Institute for Policy Analysis and Research. University of Maryland, Baltimore, MD, USA (2000)

24. Robertson, J.: Open-source content management systems (2004), http: / / www.steptwo.com.au/files/kmc_opensource.pdf (June 22, 2005)

25. Rogers, E.: Diffusion of Innovations, 4th edn. Free Press, New York (1995)

26. Simon, H.A.: Administrative behavior, 3rd edn. The Free Press, New York (1976)

27. Themistocleous, M., Irani, Z.: Evaluating Enterprise Application Integration Technologies: A Novel Frame of References. European Journal of Operational Research (2002) 
28. Tsai, J.H.: Political structure, legislative process, and corruption: comparing Taiwan and South Korea, Crime, Law and Social Change (2009) doi: 10.1007/s10611-009-9188-y

29. Tully, J., Chambers, S.: Contract or Conversation? Theoretical Lessons from the Canadian Constitutional Crisis, Politics and Society 26(1), 143-172 (1998)

30. Venkatesh, V., Davis, F.: A theoretical extension of the technology acceptance model: four longitudinal field studies. Management Science 46, 186-204 (2000)

31. Venkatesh, V., Morris, M.: Why don't men ever stop to ask for directions? Gender, social influence, and their role in technology acceptance and usage behaviour. MIS Quarterly 24, 115-139 (2000)

32. Yildiz, M.: E-government Research: Reviewing the Literature, Limitations, and Ways Forward. Government Information Quarterly 24, 646-665 (2007) 